\title{
Moisture behavior of weathered wood surfaces during cyclic wetting: measurements and modeling
}

\section{J. Niklewski ${ }^{1} \mathbb{D} \cdot$ C. Brischke ${ }^{2} \cdot$ E. Frühwald Hansson ${ }^{1} \cdot$ L. Meyer-Veltrup ${ }^{3}$}

Received: 21 December 2017 / Published online: 3 September 2018

(C) The Author(s) 2018

\begin{abstract}
The effects of weathering on the in-service moisture behavior of wood have received only limited attention so far, with much focus being on the effect of photodegradation on the hydrophobicity of the wood surface. The objective of the present study was to examine the effect of weathering surfaces on the overall moisture behavior of wood specimens exposed to short-term cyclic spraying, with special emphasis on the surface conditions involved. Specimens cut from eight different species including hardwoods and softwoods were weathered for 8 years and continuously monitored during a single-sided cyclic spraying together with a set of axially matched controls. After each spray cycle, the duration of surface wetness was evaluated by resistance moisture sensors as well as an optical approach (colorimetric) based on time-lapse images. The moisture content in the core was monitored simultaneously by use of resistance moisture sensors. The optical method correlated well with the electrical resistance measurements and provided a simple and practical measure of the areal distribution of the surface wetness. The results showed specimens with a weathered surface to sustain a wet surface for about twice the duration of their axially matched control. A considerable, albeit smaller, effect was also observed deeper in the core. By adapting the length of the wet period on the exposed boundary, the corresponding response at the core of the Norway spruce specimens was reproduced numerically.
\end{abstract}

\section{Introduction}

The concept of performance-based durability design aims at quantitatively assessing the rate of deterioration of wood products on the basis of material properties and site-specific conditions, following the methodology proposed by Meyer-Veltrup et al. (2018). This methodology involves two major challenges, one being the need for quantifying the hygrothermal conditions of the wood product and the other being

J. Niklewski

jonas.niklewski@kstr.lth.se

Extended author information available on the last page of the article 
the need for relating the hygrothermal conditions that are present to the decay activity that occurs. The literature offers a variety of mathematical models for estimating the rate of decay on the basis of the hygrothermal conditions that are present (Viitanen et al. 2010; Saito et al. 2012; Isaksson et al. 2013; Brischke and Meyer-Veltrup 2016). The hygrothermal conditions can be estimated numerically by modeling the moisture transport within the wood on the basis of climate data via moisture dynamics. As with any modeling problem, the quality of the output is governed by the uncertainty involved. This uncertainty is increasingly problematic when the hygrothermal conditions are simulated over long time-scales, since deteriorating mechanisms may induce changes in material characteristics over time, like those of checking, cracking and photodegradation.

Recently, a numerical moisture model was proposed for the use in durability assessment (Niklewski et al. 2016); however, its long-term performance remains questionable. In general, it has been observed that the measured response to moisture content induced by precipitation tends to increase over time, a behavior which is not captured by the model. Similar long-term trends have been observed in other publications where they were attributed to cracks, surface checks, staining fungi or weathering in general (Brischke and Melcher 2015; Meyer et al. 2015). Although it has been widely established that such effects increase the volume of water absorbed during wetting (Žlahtič and Humar 2016), it is not clear how the depth and nature of the damaged surface layer affect the liquid moisture uptake, the accumulation of moisture in the wood core and consequently the risk of the moisture content exceeding critical thresholds in the overall cross section of the element with respect to decay.

Weathering of wood refers to the changes in surface texture, color and chemical composition that occur when wood is exposed to various environmental conditions such as moisture, heat and solar radiation. Weathering leads to reduced hydrophobicity of the wood surface through a variety of chemical and structural changes (Kishino and Nakano 2004). Exposure to UV and visible light causes photodegradation of lignin and the formation of a cellulose-rich hydrophilic surface layer (Kalnins and Feist 1993). The depth of the affected layer is wavelength- and density-dependent with maximum depths of about 250-500 $\mu \mathrm{m}$ for UV and $900 \mu \mathrm{m}$ for visible light (Kataoka et al. 2007; Derbyshire and Miller 1981; Wang and Lin 1991); however, changes in wood color have been reported for depths of up to $2500 \mu \mathrm{m}$ (Browne and Simonson 1957). While photodegradation is mostly superficial, moisture-induced checking may extend to depths of several millimeters (Evans et al. 2003) and can thus serve as potential pathways for liquid water into the wood subsurface. Most of the photodegradation and checking occurs within weeks of exposure, but can continue for at least 6-12 months before developing to continuous slow erosion (Evans 2013; Evans et al. 2008; Kalnins and Feist 1993). Žlahtič and Humar (2016) recently found a difference in moisture absorption between specimens that had been subjected to outdoor weathering for 9 months and for 18 months, respectively. However, these tests did not exclude the occurrence of effects stemming from staining fungi.

The objective of the present paper was to study the effect of weathering surfaces on the moisture behavior of wood specimens exposed to short-term cyclic spraying. This was done by monitoring a set of pre-weathered specimens continuously during 
exposure to a sequence of cyclic single-sided spraying. The hypothesis is that the subset of specimens having a weathered surface layer absorbs more moisture during short-term wetting, remains at a higher moisture level for a longer period post-wetting and thus facilitates the migration of water deeper into the wood substrate where it may accumulate over time. This behavior should be observable from an increased duration of surface wetness combined with an increased response deeper in the core of the specimens. In the final section, a numerical model was used to further test the hypothesis by modeling the diffusion of moisture through Norway spruce (Picea abies) with different durations of surface wetness.

\section{Experimental materials and methods}

\section{Material}

The specimens that were studied were produced from boards $\left(20 \times 100 \times 500 \mathrm{~mm}^{3}\right)$ that had previously been exposed outdoors above ground over a 7-year period on a roof in Hannover, Germany. The wood species included are shown in Table 1. Boards that exhibited visible signs of decay were discarded. With the exception of Scots pine (Pinus sylvestris) sapwood, the boards that were used had previously been exposed horizontally. However, since most horizontally exposed Scots pine $(P$. sylvestris) sapwood specimens were subject to a certain degree of decay, vertically exposed specimens were used instead. Many boards exhibited small surface checks (depth $<3 \mathrm{~mm}$; length 10-30 mm). Scots pine sapwood and beech also exhibited deeper checks (depth 3-10 mm; length 30-150 mm).

Each board was prepared according to the following procedure. First, the board was cut at half its length and the weathered surface of one of the two halves was restored by planing 1-3 $\mathrm{mm}$ of the weathered surface depending on the depth of degradation. The same amount of wood was then removed from the opposite face of the axially matched specimen to obtain specimens of the same thickness. Next, $100 \mathrm{~mm}$ of the previously exposed end-grain was removed and discarded. This procedure resulted in pairs of axially matched specimens $(L=150 \mathrm{~mm} \times w=100 \mathrm{~mm})$ of the same thickness, one specimen of each pair retaining its weathered and the

Table 1 Wood species and their respective average density $(n=6)$ measured after conditioning at $\mathrm{RH}=70 \%$ and $T=20{ }^{\circ} \mathrm{C}$ (heartwood if not otherwise indicated)

\begin{tabular}{lll}
\hline Abb. & Wood species & Density $\left(\mathrm{kg} / \mathrm{m}^{3}\right)$ \\
\hline DF & Douglas fir (Pseudotsuga menziesii) & 575 \\
NS & Norway spruce (Picea abies) & 450 \\
SPS & Scots pine sapwood (Pinus sylvestris) & 560 \\
SP & Scots pine (Pinus sylvestris) & 640 \\
WRC & Western red cedar (Thuja plicata) & 355 \\
ASH & Ash (Fraxinus excelsior) & 715 \\
BEE & Beech (Fagus sylvatica) & 670 \\
OAK & Oak (Quercus robur) & 720 \\
\hline
\end{tabular}


other one being resurfaced. In total, three boards from each wood species were used, resulting in three replicates per material. One pair of axially matched specimens from each wood species is shown in Fig. 1.

The specimens were conditioned at $70 \%$ relative humidity $(\mathrm{RH})$ and $20{ }^{\circ} \mathrm{C}$ temperature to stable moisture content in the range of 11.5-13.5\%. Each specimen's weight was then determined to the nearest $0.01 \mathrm{~g}$ and its volume was obtained by the use of a caliper. The density was determined on the basis of weight and volume $\left(\mathrm{RH}=70 \%, T=20^{\circ} \mathrm{C}\right)$. All small edges of the specimens were subsequently sealed by use of silicone, weighed again and stored in air-tight containers $\left(20{ }^{\circ} \mathrm{C}, 70 \% \mathrm{RH}\right)$ until the tests were conducted.

\section{Resistance-type measurements}

\section{Measurement system}

The electrical resistance was measured every 5 min by use of commercial resistancetype moisture sensors (Omnisense type S-16) having custom-made electrodes. The electrodes were made from stainless steel (A 304) threaded rods (M2, $\emptyset=2 \mathrm{~mm}$ ) with sharp-pointed ends. The shaft of the electrodes was insulated by use of glued shrink tubing, leaving $5 \mathrm{~mm}$ of the end uninsulated. Holes were predrilled prior to inserting the electrodes, using a drill size of $\varnothing=3 \mathrm{~mm}$ to fit with the shrink tubing and $\varnothing=1.5 \mathrm{~mm}$ for the uninsulated end. Silicone was applied inside as well as around the edge of the holes in order to prevent moisture transport along the shaft of the electrode. In addition, waterproof tape was applied around the circumference of the specimen so as to protect the electrodes from water and to prevent water from running down the short sides of the specimen, one-sided wetting being achieved in this way.

The electrodes were installed at two different depths, as shown in Fig. 2. One pair of electrodes was inserted via the specimen's small edge, thus providing a precise measuring depth of $10 \pm 1 \mathrm{~mm}$. Another pair of electrodes was inserted through the rear side with the sharp-pointed tips penetrating the upper surface of the specimen,

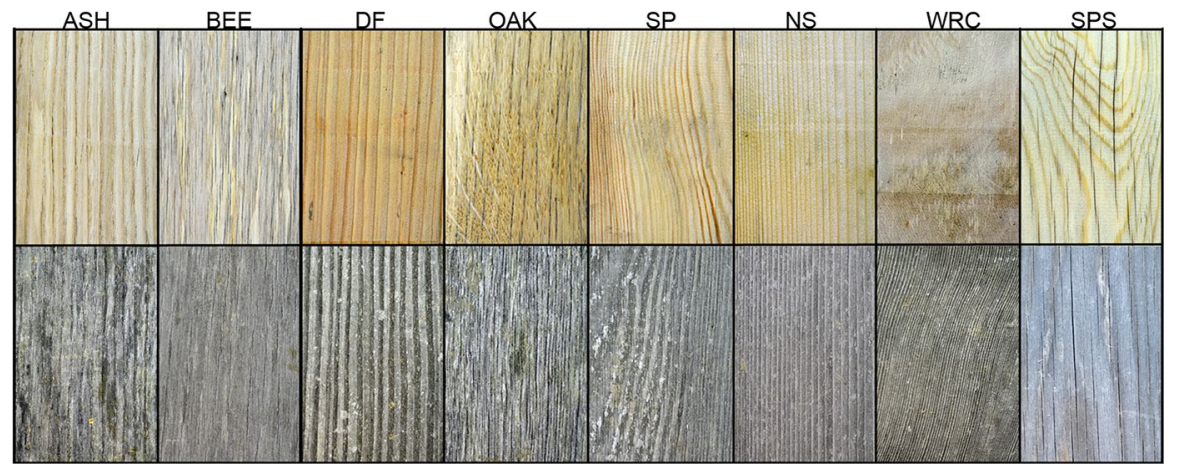

Fig. 1 Specimens with their original weathered surface (bottom) and their axially matched restored specimens (top). The contrast shown has been increased for enhanced visibility 

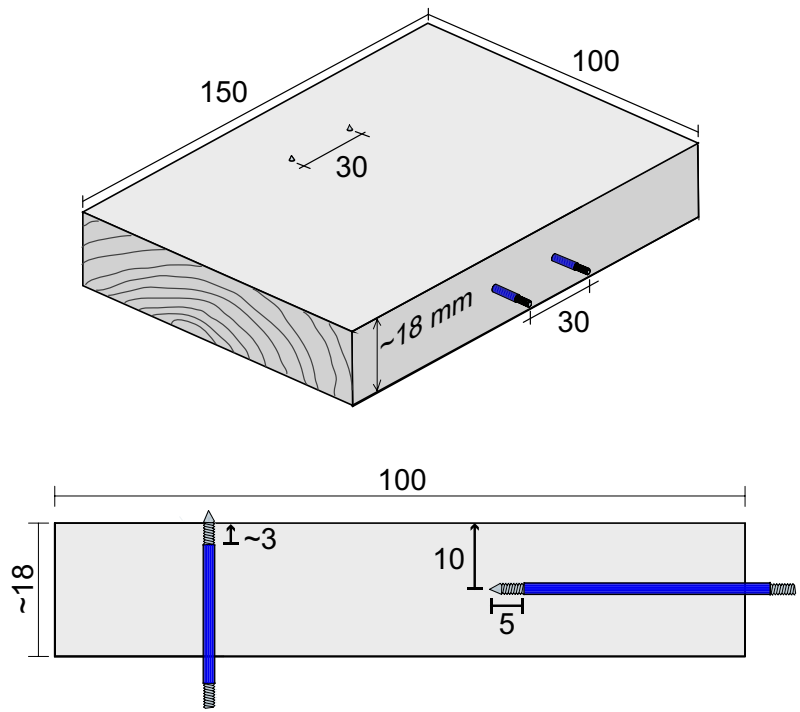

Fig. 2 Schematic illustration of a full-test specimen and a cross section, including the dimensions involved and the locations of the electrodes. Units in $(\mathrm{mm})$

approximately $3 \mathrm{~mm}$ of the electrode being in contact with the wood. A thin layer of silicone was then applied around the tip of the pin at the wood-electrode interface to prevent water from penetrating the wood via the electrode. No electrode was in direct contact with a crack.

\section{Limitations and accuracy}

The electrical resistance decreases by several orders of magnitude between $7 \%$ and the fiber saturation point (FSP) at approximately $25-30 \%$ moisture content (see e.g., Fredriksson et al. 2013). When using pin-type electrodes, the measured resistance is largely governed by the local moisture content at the wood-electrode interfaces (Skaar 1988; Norberg 1999; Zelinka et al. 2015). The resistance decreases with increasing moisture content, also above the FSP, although the moisture dependency is far less pronounced in the high moisture content range (Stamm 1929). Calibration curves extending beyond the FSP exist (see Fredriksson et al. 2013; Brischke et al. 2007; Otten et al. 2017), but high precision and careful calibration is necessary, since small deviations from the calibration curve lead to large errors in the recorded moisture content.

Species-specific calibration curves for NS, BEE, DF, SPS, SP and OAK based on measurements by Otten et al. (2017) were used here, these being calibrated from the same material as used in the present study. The curve for NS was also used for WRC and the curve for BEE was used for ASH, as species-specific calibration curves were unavailable in the same reference. A systematic error stemming from the devicedependency of the calibration curves is expected, primarily due to differences in electrode type. This was deemed acceptable as the main focus of the present work 
is to study relative differences in terms of moisture changes over time. Comparison between gravimetric measurements and electrical measurements using the measurement system employed in the present study indicated that the curve from Otten et al. (2017) underestimated the moisture content of Norway spruce by about 1 pp at $15 \%$ moisture content, with a smaller error being obtained at $22 \%$ moisture content.

The surface measurements employed in the present study overestimate the resistance of the wood relative to the calibration curves employed. This is due to the electrical resistance being higher near the wood surface (Fredriksson et al. 2015) and device-dependent factors such as smaller electrodes (Hjort 1996; Björngrim et al. 2017). These factors have a disproportional effect in the over-hygroscopic range where the resistance is sensitive to changes in moisture content. As a consequence, large moisture fluctuations in the over-hygroscopic moisture range appear small, and transitions between the hygroscopic to the superhygroscopic regions appear as an abrupt change in the rate of moisture content change (Yamamoto et al. 2013).

\section{Optical appearance, $\Delta E^{*}$}

Optical appearance was used here as a binary metric, indicating whether the surface was wet or dry. A conventional digital camera that took 20 images/h monitored the appearance of the specimens over time. Due to camera failure, images for Douglas fir (DF) and for Scots pine heartwood (SP) were not included.

Using the MATLAB (2017) image processing toolbox, the color images were processed in the $L^{*} a * b *$ (lightness/green-red/blue-yellow) color space. A Gaussian smoothing filter $(\sigma=3)$ was employed to reduce effects related to pixel displacement, induced by swelling and by cupping. The difference between two colors was defined according to the CIE76 (International Commission on Illumination) definition of perceptual color difference:

$$
\Delta E^{*}=\sqrt{\Delta L^{* 2}+\Delta a^{* 2}+\Delta b^{* 2}},
$$

where $\Delta E^{*}$ is the Euclidian distance between two colors $\left(L_{1}^{*}, a_{1}{ }^{*}, b_{1}{ }^{*}\right)$ and $\left(L_{2}{ }^{*}\right.$, $\left.a_{2}{ }^{*}, b_{2}{ }^{*}\right)$ in the color space. The perceived color change over time, $\Delta E^{*}(\mathrm{t})$, was further defined as the difference between the initial color, prior to the first spray and the color of each consecutive image. The calculations were performed on a pixel-bypixel basis.

\section{Test setup and exposure conditions}

The test setup and the climate sequence are shown in Fig. 3. For each test, twelve specimens were mounted on racks inside a climate chamber (CTS C-40/1000) having a floor area of $1 \times 1 \mathrm{~m}^{2}$. The specimens were fixed with an inclination of $30^{\circ}$ to avoid standing water. Two full-cone spray nozzles with spray angles of $45^{\circ}$ provided a uniform distribution of spray over the floor area with a total flow rate of $1.4 \mathrm{l} /$ min, which corresponds to intense precipitation of $84 \mathrm{~mm} / \mathrm{h}$. A thermocouple was installed inside the water inlet to monitor the water temperature and ensure a water 

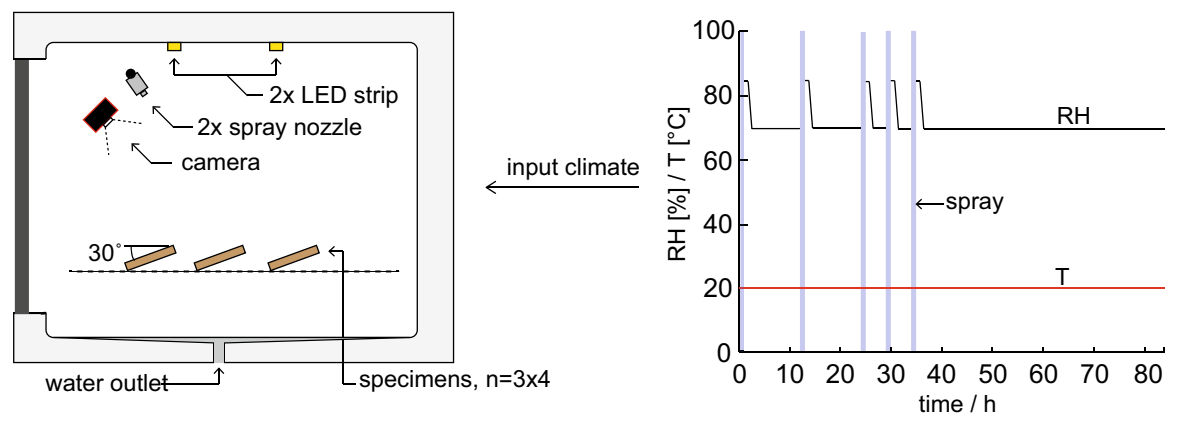

Fig. 3 Side view of the climate chamber with a set of specimens organized in a $3 \times 4$ grid (left) and the climate sequence that was used serving as input (right)

temperature of $20 \pm 2{ }^{\circ} \mathrm{C}$. Each spray period was $1 \mathrm{~h}$ long, the periods involved start at the times $t=0 ; 12 ; 24 ; 30$; and $36 \mathrm{~h}$. After the fifth spray, the specimens were left for $48 \mathrm{~h}$ before the test was terminated. Due to the high moisture load after each spray, the relative humidity was slowly reduced, following a controlled sequence. The air circulation gave an air velocity of approximately $1.0-1.2 \mathrm{~m} / \mathrm{s}$, as measured locally at the surface of the specimens by use of a hot thread anemometer. The air velocity was found to be higher when measured in the near vicinity of the floor and the walls. The racks were thus elevated $200 \mathrm{~mm}$ from the floor, the specimens being placed at a minimum distance of $100 \mathrm{~mm}$ from the walls, so as to ensure a uniform air velocity.

\section{Data post-processing}

\section{Duration of surface wetness}

The duration of surface wetness was described by two different metrics, whereof one based on optical appearance and the other based on electrical resistance. The transition from a wet to a moist surface coincides with an abrupt increase in the rate of resistance change, thus causing a similar, concurrent, response in the measured moisture content, $u_{\mathrm{R}}(t)$. The same event is also seen from the color change, as $\Delta E^{*}(t)$ stabilizing near zero. The timings of the two events, which are hereafter denoted $t\left(u_{\mathrm{R} \text {,wet }}\right)$ and $t\left(\Delta E_{\mathrm{wet}}^{*}\right)$, were estimated by the default MATLAB (2017) algorithm 'findchangepts'.

Figure $4 \mathrm{a}, \mathrm{b}$ shows how the MATLAB (2017) algorithm works using two typical time-series of $\Delta E^{*}(t)$ and $u_{\mathrm{R}}(t)$, respectively. In brief, the time-series are subdivided into linear segments, the number of segments depending upon prescribed precision criteria. Reducing the prescribed precision effectively reduces the number of segments by allowing larger residuals, and vice versa. The mathematical definitions involved can be found in the MATLAB (2017) manual. A single precision criterion was used for the moisture content and for the color time-series, respectively. The timing of $t\left(u_{\mathrm{R}, \text { wet }}\right)$ was set equal to the start of the segment having the largest negative slope (Fig. 4a), while the timing of $t\left(\Delta E_{\text {wet }}^{*}\right)$ was estimated from the total width 
(a)

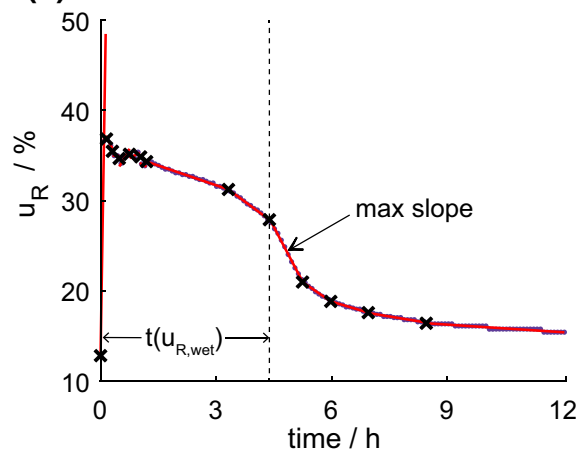

(b)

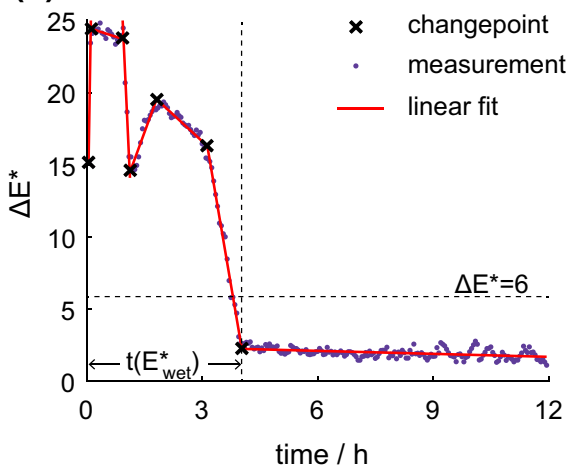

Fig. 4 An example of linear segmentation of $\mathbf{a} u_{\mathrm{R}}(t)$ and $\mathbf{b} \Delta E^{*}(t)$, as well as calculation of $t\left(\Delta E_{\text {wet }}^{*}\right)$ and $t\left(u_{\mathrm{R}, \mathrm{wet}}\right)$

of the peak interval (Fig. 4b). The width of the peak interval was estimated as the time between the start of the spray and the first change-point below a threshold of $\Delta E^{*}=6$. If $\Delta E^{*}(t)$ never decreased below the threshold, it was assumed that the pixel did not regain its original color before the start of the next spray event.

\section{Moisture conditions}

The moisture conditions in the surface layer and in the core of the specimens were assessed by calculating (1) the cumulative time during which surface electrodes indicated moisture content above $25 \%$ and (2) the amplitude of the response as measured at a depth of $10 \mathrm{~mm}$. The cumulative time above $25 \%$ moisture content was calculated as the sum of time-increments during which the moisture content exceeded $25 \%$. The response at $10 \mathrm{~mm}$, hereafter, denoted $\Delta u_{\mathrm{R}, \max }$, was quantified as follows:

$$
\Delta u_{\mathrm{R}, \max }=u_{\mathrm{R}, \max }(t)-u_{\mathrm{R}, \min }(t),
$$

where $u_{\mathrm{R}, \min }$ and $u_{\mathrm{R}, \max }$ are the minimum (initial) and the maximum measured moisture content values at a depth of $10 \mathrm{~mm}$, respectively, where the latter occurred a few hours after the final spray cycle. As such, $\Delta u_{R, \max }$ describes the amplitude of the response over the full test period of $84 \mathrm{~h}$.

\section{Experimental results and discussion}

\section{Moisture content, $u_{R}(t)$}

Figure $5 \mathrm{a}, \mathrm{b}$ shows the average measured moisture content of the NS specimens over a full test period (a) and a one-spray cycle (b). Restored and weathered samples are hereafter indicated with subscripts $r$ and $w$, respectively. The moisture 

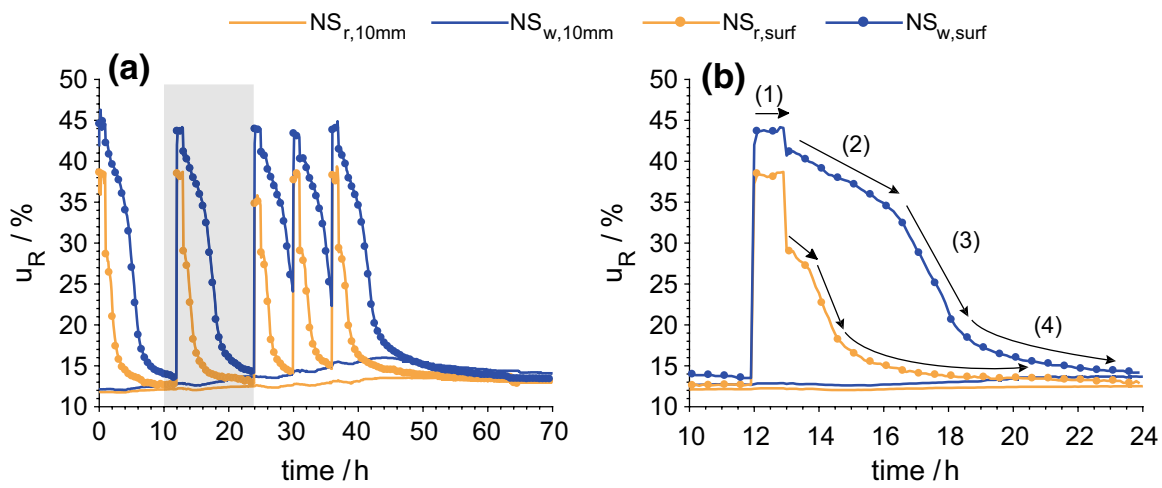

Fig. 5 Average variation (three replicates) in moisture content of the weathered and the restored samples of NS, measured near to the surface of the wood and in the core of the wood. Markers are placed in 30-min intervals

content measured in the core of the samples requires no clarification, but the surface measurements exhibit features that are related to the functionality of resistancetype measurements. In each wetting/drying cycle, the measured moisture content at the surface went through four distinct phases, as shown in Fig. 5b. First, a liquid film was formed on the wood surface $(t=0 ; 12 ; 24 ; 30 ; 36 \mathrm{~h})$, effectively closing the electrical circuit between the surface electrodes, resulting in a 1-h peak. As the liquid film dissipated, the moisture content immediately dropped a few points to values within the range between 27 and 40\%, marking a transition to the second phase where $u_{\mathrm{R}}(t)$ stabilized and decreased slowly at an approximately constant rate. Although not reflected by the measurements, the rate of evaporation here should be high since free water is released from the cell cavities. The seemingly low drying rate is related to the moisture content being in the superhygroscopic moisture range (see "Limitations and accuracy" section). The start of the third phase is characterized by an accelerating apparent drying rate, which generally occurred in the range $u_{\mathrm{R}}=25-35 \%$, indicating that the measured moisture content has transitioned to the hygroscopic moisture range. Finally, in the fourth phase the moisture content converges toward equilibrium with the exterior air.

In Fig. 5b, it can be noted that the measured moisture content at which the transition point between phase two and phase three occurs was subject to variation, specimens with a weathered surface generally having a higher value. This is likely due to the measured moisture content being affected by the moisture distribution between the surface and a depth of $3 \mathrm{~mm}$. The abrupt change in slope indicates the absence of liquid water but the moisture distribution, and thus the measured resistance, may still differ between the specimens.

\section{Optical appearance, $\Delta E^{*}(t)$}

Figure 6 shows the changes in surface color over time that occurred for an axially matched set of BEE, which is representative of the general behavior of most 
Fig. 6 Changes in surface color for a single weathered (subscript w) and a single restored (subscript r) specimen of beech (BEE) over time

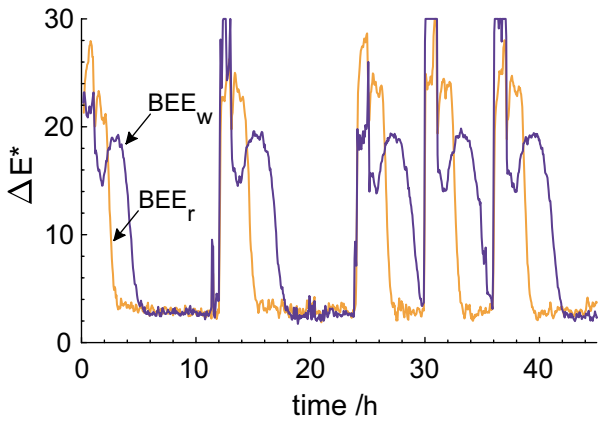

specimens. $\Delta E^{*}(t)$ was here calculated as the median pixel value over a rectangular region $\left(40 \times 15 \mathrm{~mm}^{2}\right.$ in size $)$ enclosing the surface electrodes, this area being representative of where the electrical measurements were taken. Due to the presence of a liquid film on the wood surface, $\Delta E^{*}(t)$ peaked for 1-h per spray cycle $(t=0 ; 12 ; 24 ; 30 ; 36 \mathrm{~h})$. The color then stabilized and remained relatively constant for a distinct period during which all specimens with weathered surfaces and most of the specimens with restored surfaces exhibited values of around $15<\Delta E^{*}<30$, whereas the NS and SPS specimens with restored surfaces exhibited lower values, of $10<\Delta E^{*}<15$. Subsequently, $\Delta E^{*}(t)$ declined rapidly toward $\Delta E^{*} \approx 0$, indicating that the visible cavities were emptied of liquid water. Generally, $\Delta E^{*}(t)$ did not decrease all the way to zero but stabilized at around 2-5 due primarily to pixel displacement stemming from swelling and small changes in illumination.

\section{Comparison of $t\left(\Delta E_{\text {wet }}^{*}\right)$ with $t\left(u_{\mathrm{R}, \text { wet }}\right)$}

For comparison with the electrical measurements obtained, $t\left(\Delta E_{\text {wet }}^{*}\right)$ was calculated as the median pixel value at the location of the electrodes. Generally, a small rectangular area approximately $40 \times 15 \mathrm{~mm}^{2}$ in size where both electrodes were present was suitable for this purpose. In cases with large variations between the two electrodes, the region was reduced in size to include only the electrode with the lower value.

Figure 7 shows $t\left(\Delta E_{\text {wet }}^{*}\right)$ as compared with $t\left(u_{\mathrm{R} \text {,wet }}\right)$ following the first spray sequence $(0<t<12 \mathrm{~h})$. The correlation between the two metrics was high, although the incident of $t\left(\Delta E_{\text {wet }}^{*}\right)$ generally came shortly after the incident of $t\left(u_{\mathrm{R} \text {,wet }}\right)$. This would suggest that the moisture front remains visible during the first drying cycle and does not recede below the visible surface, as would otherwise be indicated by a later incidence of $t\left(u_{\mathrm{R} \text {,wet }}\right)$, since the electrical measurements extend to a depth of $3 \mathrm{~mm}$.

The resistance-based method was useful for cross-validating the method based on optical appearance, although it is subject to various uncertainties. In fact, larger discrepancies $(>1 \mathrm{~h})$ were limited to time-series in which the exact point at which the increase in slope began was difficult to determine, such as when the slope increased gradually over the course of $0.5-1 \mathrm{~h}$ instead of abruptly. The optical analysis was not subject to the same difficulties, since the width of the peak interval of $\Delta E$ was 
Fig. 7 Comparison between times of wetness $t\left(\Delta E_{\text {wet }}^{*}\right)$ and $t\left(u_{\mathrm{R}, \mathrm{wet}}\right)$ for the first spray cycle, as estimated on the basis of optical and electrical measurements, respectively. Both weathered specimens and restored ones are included

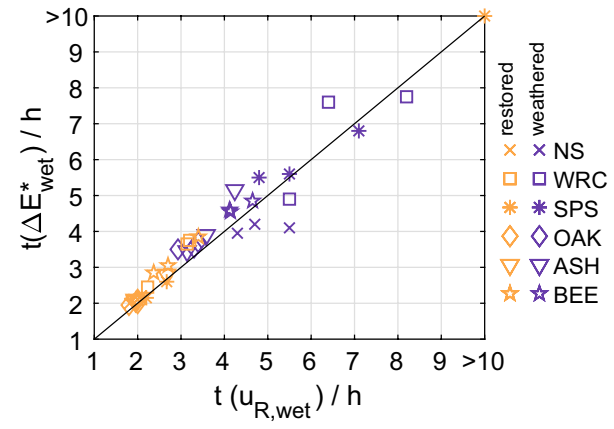

consistently well defined. The drawbacks found, however, include the need for constant illumination and the fact that non-observable water may still remain in micropores, even after the surface appears to be dry (Hall and Hoff 2012). Nevertheless, the colorimetric analysis was deemed superior to the resistance-based metric and was therefore employed, in the sections that follow, for assessing the duration of surface wetness.

\section{Areal distribution, $t\left(\Delta E_{\text {wet }}^{*}\right)$}

The areal variations in $t\left(\Delta E_{\text {wet }}^{*}\right)$ of four axially matched pairs are shown in Fig. 8 together with color images (sRBG) taken prior to spraying. The frames around the pins mark the region that can be compared to the values in Fig. 7. Most specimens exhibited uniform drying patterns, similar to those observed in the OAK specimen. Very few specimens exhibited irregular drying patterns, such as those observed in the case of one of the SPS boards. The reason for such irregular drying patterns was not easy to explore, but they were found to generally occur in specimens having deeper cracks or variations in surface roughness. The restored WRC specimen is an example of the latter. Finally, the latewood of some specimens, for example in one of the SPS boards, was visibly wet for a longer period than the earlywood.

The irregular drying patterns highlight one of the primary limitations of using point-type electrical sensors for the monitoring of surface moisture content, since the type of system is limited to local measurements. In addition, in the case of variations between the two electrodes in terms of moisture content, electrical resistance is limited by the electrode that is lower in moisture content. These measurements thus indicate the lower moisture content in contact with one of the electrodes.

\section{Comparison of axially matched specimens}

Figure 9a, b shows the cumulative duration when the surface was visibly wet (a) and the cumulative duration when the output of the electrical surface sensors exceeded 25\% moisture content (b). Both metrics show that the restored specimens spend less time in wet conditions. From Fig. 9b, it appears that the time spent above 25\% increases with each spray period (see BEE, ASH, SPS), a feature that is not as pronounced in Fig. 9a. This is likely due to moisture accumulation below the visible 


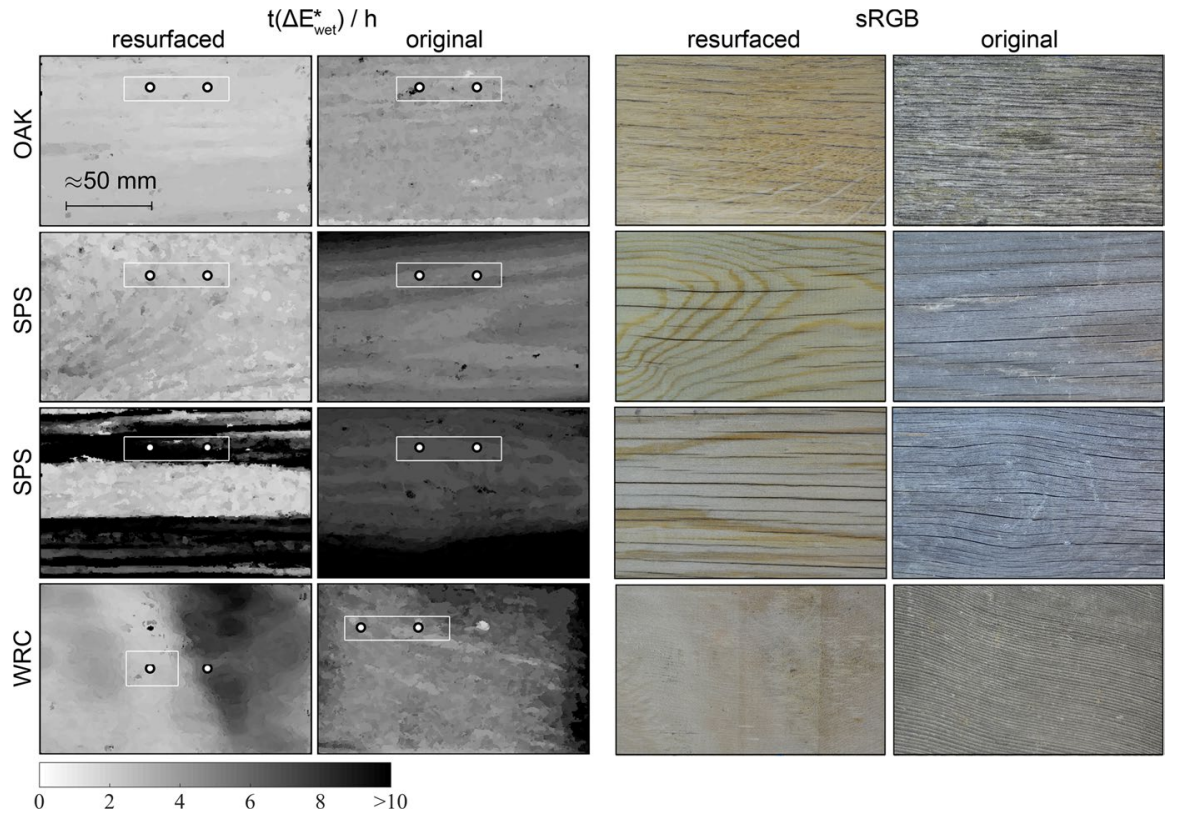

Fig. 8 Pair of axially matched specimens per species are presented as images of color variation values at critical surface wetness point (left columns), and as sRGB images taken prior to wetting (right columns). The markers show the locations of the electrodes
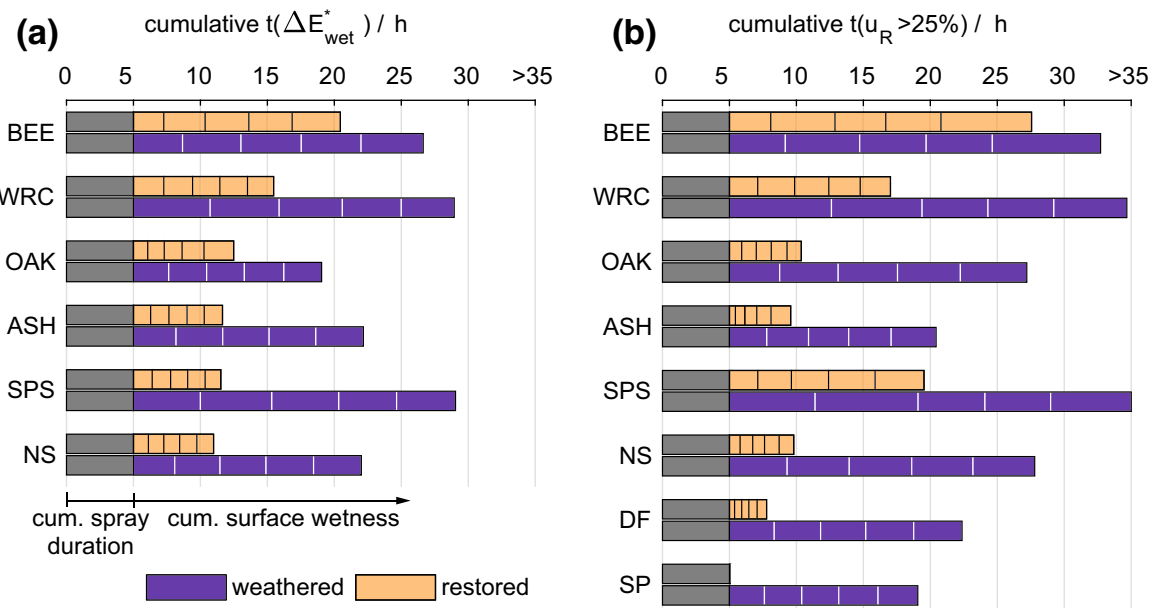

Fig. 9 Differences between axially matched specimens: a cumulative duration when the surface was visibly wet and b cumulative duration when the apparent moisture content exceeded $25 \%$ near the surface. Note that one specimen of SPS with large cracks has been excluded from the data 
layer (depth 1-3 mm), where increasing moisture content has a disproportional effect on the electrical measurements.

Figure 10 shows the maximum increase in moisture content in the core of the specimens, $\Delta u_{\mathrm{R}}$, calculated from Eq. 2. Each pair of specimens is connected by a line, where a positive slope indicates that the specimen with a weathered surface exhibited a larger response than its axially matched restored specimen. The increase in moisture content in the core was small, but the specimens with weathered surfaces generally exhibited a larger response in their core than their axially matched restored specimens. The heartwood specimens (SP and DF) and the specimens with larger cracks (SPS and BEE) were less consistent in this regard, with some of the restored specimens exhibiting higher $\Delta u_{\mathrm{R}}$. The specimens with cracks (SP and DF) also exhibited very large variations, for example restored BEE specimens having values from $0.5 \%$ to more than $5 \%$, thus indicating that the effect of the cracks was pronounced.

The results of the present study show the effects of weathering to be most pronounced at the surface, which is in agreement with the results by Žlahtič and Humar (2016) where it was shown that mainly the short-term water uptake increased due to weathering. In one-dimensional capillary absorption, such as in the floating test, the moisture uptake of porous materials is generally found to be proportional to the square root of the time, $t^{1 / 2}$. Weathered samples, however, tend to deviate from this behavior at the initial stage of testing (Žlahtič and Humar 2016; Welzbacher and Rapp 2004). Deviations from the square root of time proportionality involved may occur due to material inhomogeneity, gravitational effects and/or dimensional changes during absorption (Hall and Hoff 2012). The initial deviations observed in measurements on pre-weathered wood can be seen as quite likely being related to the inhomogeneity between the weathered surface and the bulk material, where water is easily absorbed into the hydrophilic substance of wood and quickly reaches the intact subsurface, after which the absorption rate becomes basically equal to that of non-weathered wood.

From a modeling standpoint, this moisture-buffering effect of weathered surfaces can be regarded as a boundary effect. In brief, the increased short-term absorption of

Fig. 10 Maximum moisture increase in the core of the specimens. Note that one restored DF specimen is excluded due to sensor outage prior to reaching its maximum value

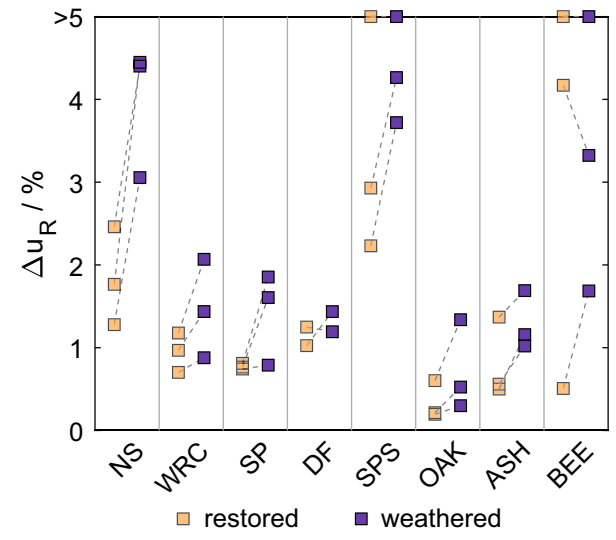


liquid water increases the duration of the surface wetness that is found, which effectively increases the mass of the water that diffuses through the subsurface and into the core of the wood. In the section that follows, the possibilities of modeling this effect are explored.

\section{Numerical model}

A numerical model of the moisture diffusion in Norway spruce was used to explore the relationship between surface wetting and the corresponding response deeper in the material. The net moisture flux within the material is commonly described by Fick's second law of diffusion with the moisture gradient as the driving potential, which in one dimension is written as:

$$
\frac{\mathrm{d} u}{\mathrm{~d} t}=\frac{\mathrm{d}}{\mathrm{d} x}\left(D(u) \frac{\mathrm{d} u}{\mathrm{~d} x}\right),
$$

where $u(\%)$ and $\mathrm{D}(u)\left(\mathrm{m}^{2} / \mathrm{s}\right)$ are the moisture content by weight and the diffusion coefficient, respectively. Here, the average of the radial and tangential diffusion coefficients determined by Koponen (1984) was used (see Fig. 11). The diffusion coefficient increases with both temperature and moisture content. However, since the wood temperature is approximately constant here, only the moisture dependency is considered. In the absence of liquid water on the wood surface, the boundary condition can be described by a surface flux, $q\left(\mathrm{~kg} / \mathrm{m}^{2} \mathrm{~s}\right)$, as follows:

$$
\frac{q}{\rho}=k_{\mathrm{p}}\left(p_{\mathrm{vw}}-p_{\mathrm{v}}\right),
$$

where $k_{\mathrm{p}}\left(\mathrm{kg} /\left(\mathrm{m}^{2} \mathrm{~Pa} \mathrm{~s}\right)\right), p_{\mathrm{vw}}(\mathrm{Pa}), p_{\mathrm{v}}(\mathrm{Pa})$ and $\rho\left(\mathrm{kg} / \mathrm{m}^{3}\right)$ are the mass transfer coefficient, the vapor pressure at the wood surface, the ambient vapor pressure and the dry density of wood, respectively. The mass transfer coefficient is primarily dependent

Fig. 11 Diffusion coefficient from Koponen (1984), calculated from the average of the tangential and radial diffusion coefficients

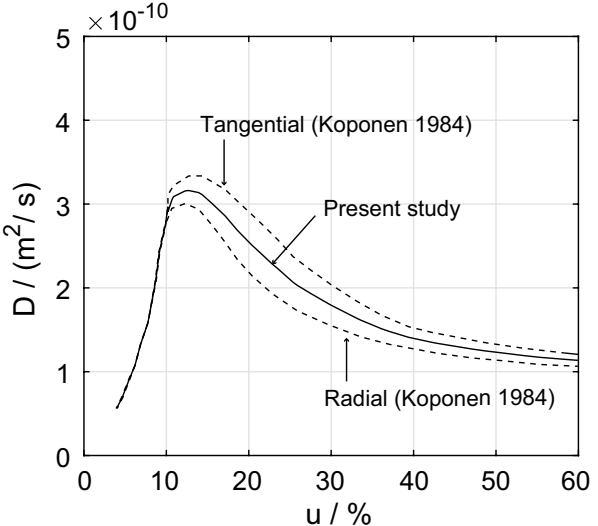


on air velocity. According to a literature review by Wadsö (1993), values of $k_{\mathrm{p}}$ are usually measured in the range $1-30 \times 10^{-9} \mathrm{~kg} /\left(\mathrm{m}^{2} \mathrm{~Pa} \mathrm{~s}\right)$. In the present analysis, a value of $15 \times 10^{-9} \mathrm{~kg} /\left(\mathrm{m}^{2} \mathrm{~Pa} \mathrm{~s}\right)$ was used. Equation 4 implies that the vapor pressure at the wood surface is in equilibrium with the moisture content at the wood surface, where the sorption isotherm describes the relationship between the two. The sorption isotherm was described by a Hailwood-Horrobin-type function of the following form:

$$
u_{\mathrm{eq}}=\frac{\phi}{A+B \cdot \phi-C \cdot \phi^{2}} \text {, }
$$

where $u_{\text {eq }}(\mathrm{kg} / \mathrm{kg})$ is the equilibrium moisture content and $\Phi(\mathrm{Pa} / \mathrm{Pa})$ is the relative vapor pressure $(\Phi=\mathrm{RH} / 100)$. The coefficients were set to $A=5.84 \times 10^{-3}, B=0.156$ and $C=0.116$ as determined by Time (1998). The specific sorption isotherm provides an equilibrium moisture content of $12-13 \%$ at $\mathrm{RH}=70 \%$, which is in close agreement with the initial moisture content of the specimens involved.

Although moisture transport during wetting is a combination of diffusion and capillary transport, the capillary part is not explicitly modeled here. It is instead assumed that diffusion is the primary mode which governs the transport of moisture deeper into the material, while capillary action is limited to the surface layer. Wetting of the surface is modeled by assigning a fixed value of $30 \%$ moisture content to the boundary, in analogy with the findings of Meijer and Militz (2000) who modeled single-sided wetting of spruce. Here, a moisture content of $30 \%$ is applied when the surface is wet, as determined by the optical measurements, i.e., $t\left(\Delta E_{\text {wet }}^{*}\right)$.

Measured values of $t\left(\Delta E_{\text {wet }}^{*}\right)$ per spray cycle varied between 2.0 and 2.2 and from 4.0 to $4.6 \mathrm{~h}$ for the restored and the weathered specimens, respectively, with no significant difference observed between the five spray cycles (see Fig. 9a). For simplicity's sake, the duration of the surface wetness was set here to fixed values of 2.1 (restored specimens) and 4.3 (weathered specimens) hours per spray. The relative humidity and the temperature are obtained from Fig. 3.

As can be understood, this method is not feasible to use for predictive purposes, such as during outdoor exposure, since it involves the use of measured data that are generally not available. It should be emphasized, therefore, that the model is used for exploratory rather than predictive purposes. In addition, the boundary condition does not accurately describe the moisture conditions at the surface, since the moisture content there is governed by capillary forces and the actual moisture content is above $30 \%$.

Each specimen was modeled as a one-dimensional element having a length of $L=17 \mathrm{~mm}$, where $x=0$ represents the exposed boundary. The initial moisture content was set to $12.0 \%$, consistent with the equilibrium moisture content of the sorption isotherm at $\mathrm{RH}=70 \%$ and the wood density was set to $450 \mathrm{~kg} / \mathrm{m}^{3}$. 


\section{Numerical results and discussion}

Figure 12 shows the variations in simulated and in measured moisture content at the surface and at a depth of $10 \mathrm{~mm}$, respectively. The simulated moisture content at the surface is represented by the maximum moisture content found between $x=0$ and $x=3 \mathrm{~mm}$ at each time step. Qualitatively, the model captures the main features of the experimental results quite well. Both the numerically obtained results and the experimental results predict a rather small effect of weathering in the core of the sample, despite the considerable effect at the surface.

Failure to predict the timing of the peak value in the core of the specimens with weathered surfaces (see marker A) is likely related to the lack of consideration of capillary action, which is pronounced in the damaged surface layer. The earlier measured peak value can be explained by the smaller distance of non-damaged wood between the moisture front and the electrodes located at a depth of $10 \mathrm{~mm}$. The model assumes homogenous material with a saturated surface at $x=0$, while in practice, the damaged surface layer is at least 1-mm thick. The moisture front rapidly reaches the depth of the intact surface layer where saturation vapor pressure is maintained and the actual distance of non-damaged wood, through which moisture needs to migrate through diffusion, is thus smaller in the specimens having a damaged surface.

Finally, it should be emphasized that the experiments of the present study were performed under a certain set of conditions with regard to relative humidity, temperature and wind velocity, all of which are related to the evaporation rate. As such, the duration of surface wetness applied to the present analysis is valid under these
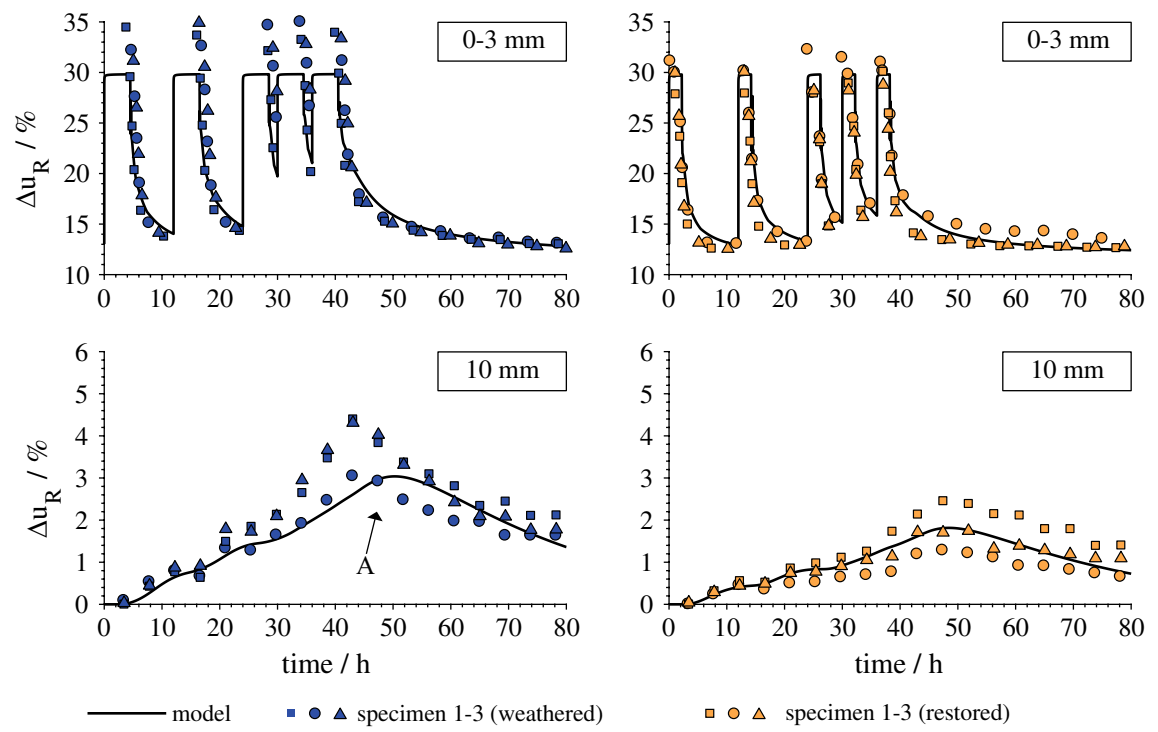

Fig. 12 Numerically obtained results (solid lines) plotted together with the measured results obtained from weathered (left column) and restored (right column) NS samples, respectively. $\Delta u_{\mathrm{R}} 10 \mathrm{~mm}$ shows the accumulation of moisture (\%) in the core of the board with duration of wetting exposure 
specific conditions. The numerical analysis performed here should thus be regarded as exploratory rather than predictive. In future research, a general relationship between external variables (such as RH, $T$ and wind velocity), surface characteristics and duration of surface wetness should be established.

\section{Practical implications}

The results show that superficial damage had a pronounced effect on the cumulative duration of surface wetness under cyclic spraying, which in turn increased the amount of moisture diffusing into the wood core. As the weathered surface layer is generally fully established within 1 year of outdoor exposure (Evans 2013), a concurrent change in moisture behavior over the same time period should be expected. Weathering thus serves as a plausible explanation for the increasing trends in moisture content observed by Brischke and Melcher (2015), Meyer et al. (2015) and Niklewski et al. (2016), as was hypothesized above ("Introduction" section). This further suggests that the moisture behavior will, to some extent, remain stable after about 1 year of exposure, which is important for performance-based modeling where models and measurements are extrapolated over longer time periods. Further research is needed to confirm this suggestion.

On the other hand, cracking as well as biotic factors (e.g., decay and staining fungi) can cause local changes in moisture conditions after several years of exposure. Effects of cracking have so far not been considered in performance-based modeling. Although not the focus of the present study, the measurements indicated that deep cracks (3-10 $\mathrm{mm}$ depth) had a pronounced effect on the moisture content of the surrounding wood tissue. Local microclimates in the vicinity of cracks can possibly provide favorable growth conditions for fungal decay, and further research is needed to study the effects of cracks on the local moisture conditions and their role in fungal colonization of wood.

Finally, experiments carried out on freshly planed specimens, such as the vast majority of laboratory experiments, are not entirely representative of the actual inservice long-term moisture performance of wood subjected to weathering. As shown by the present study, the discrepancy is particularly pronounced in the exposed surface layer where the cumulative duration of surface wetness, which is commonly used for durability assessment, differed by a factor of about two. In order to reproduce the actual long-term moisture behavior of wood products, experiments could be based on pre-weathered material.

\section{Conclusion}

The effect of weathered surfaces on the moisture conditions of wood was investigated by means of time-lapse colorimetric analysis and resistance-type moisture sensors. Subsequent to short-term spraying, surfaces with superficial damage remained wet for about twice as long as those of axially matched specimens whose surface was restored by planing. The difference was still greater in terms of duration 
of having a moisture content of above $25 \%$, thus indicating increased susceptibility to decay development. Measurements and complementary numerical simulation showed that the increased duration of surface wetness caused the rain-induced moisture fluctuations of the wood core to increase in amplitude. This implies that outdoor weathering of lateral wood surfaces can cause a gradual change in moisture behavior over time, an effect that should be considered when extrapolating short-term models and measurements for assessing the long-term performance of wood products subjected to superficial degradation.

Finally, deep cracks had a pronounced effect on the moisture conditions, both in the wood core and on the surface. The local microclimate in the vicinity of cracks could possibly provide favorable growth conditions for fungal decay, but more research is needed to establish the role of cracks on the moisture conditions and fungal colonization of wood.

Acknowledgements J. Niklewski and C. Brischke acknowledge the financial support for this work that was received from the Wood Wisdom-net research project Durable Timber Bridges (DuraTB). E. Frühwald Hansson acknowledges the funding for this work that was received from the Swedish Research Council Formas (Grant Number: 2012-386).

Open Access This article is distributed under the terms of the Creative Commons Attribution 4.0 International License (http://creativecommons.org/licenses/by/4.0/), which permits unrestricted use, distribution, and reproduction in any medium, provided you give appropriate credit to the original author(s) and the source, provide a link to the Creative Commons license, and indicate if changes were made.

\section{References}

Björngrim N, Fjellström PA, Hagman O (2017) Resistance measurements to find high moisture content inclusions adapter for large timber bridge cross-sections. BioResources 12(2):3570-3582

Brischke C, Melcher E (2015) Performance of wax-impregnated timber out of ground contact: results from long-term field testing. Wood Sci Technol 49:189-204

Brischke C, Meyer-Veltrup L (2016) Modelling timber decay caused by brown rot fungi. Mater Struct 49:3281-3291

Brischke C, Rapp AO, Bayerbach R (2007) Measurement system for long-term recording of wood moisture content with internal conductively glued electrodes. Build Environ 43:1566-1574

Browne FL, Simonson HC (1957) The penetration of light into wood. For Prod J 7(10):308-314

Derbyshire H, Miller ER (1981) The photodegradation of wood during solar irradiation. Holz RohWerkst 39:341-350

Evans PD (2013) Weathering of wood. In: Rowell RM (ed) Handbook of wood chemistry and wood composites, Chapter 7, 2nd edn. Taylor and Francis (CRC Press), Boca Raton

Evans PD, Donnelly CF, Cunningham RB (2003) Checking of CCA-treated radiate pine decking timber exposed to natural weathering. For Prod J 53(4):66-71

Evans PD, Urban K, Chowdhury MJA (2008) Surface checking of wood is increased by photodegradation caused by ultraviolet and visible light. Wood Sci Technol 42:251-265

Fredriksson M, Wadsö L, Johansson P (2013) Small resistive wood moisture sensors: a method for moisture content determination in wood structures. Eur J Wood Prod 71:515-524

Fredriksson M, Claesson J, Wadsö L (2015) The influence of specimen size and distance to a surface on resistive moisture content measurements in wood. Math Probl Eng. https://doi. org/10.1155/2015/215758

Hall C, Hoff W (2012) Water transport in brick, stone and concrete, 2nd edn. Taylor and Francis (Spon Press), New York

Hjort S (1996) Full-scale method for testing moisture conditions in painted wood paneling. J Coat Technol 68:31-39 
Isaksson T, Brischke C, Thelandersson S (2013) Development of decay performance models for outdoor timber structures. Mater Struct 46:1209-1225

Kalnins MA, Feist WC (1993) Increase in wettability of wood with weathering. For Prod J 43(2):55-57

Kataoka Y, Kiguchi M, Williams RS, Evans PD (2007) Violet light causes photodegradation of wood beyond the zone affected by ultraviolet light. Holzforschung 61:23-27

Kishino M, Nakano T (2004) Artificial weathering of tropical woods. Part1: changes in wettability. Holzforschung 58:552-557

Koponen H (1984) Dependence of moisture diffusion coefficient of wood and wooden panels on moisture content and wood properties. Pap Puu 66(12):740-745

MATLAB (2017) version 2017a

Meijer MD, Militz H (2000) Moisture transport in coated wood. Part 1: analysis of sorption rates and moisture content profiles in spruce during liquid water uptake. Holz Roh- Werkst 58(5):354-362

Meyer L, Brischke C, Kasselmann M (2015) Holzfeuchte-Monitoring im Rahmen von Dauerhaftigkeitsprüfungen - Praktische Erfahrungen aus Freilandversuchen. (Wood moisture content monitoring in durability tests - practical experience in field studies) (In German). Holztechnologie 56:11-19

Meyer-Veltrup L, Brischke C, Niklewski J, Frühwald-Hansson E (2018) Design and performance prediction of timber bridges based on a factorization approach. Wood Mater Sci Eng 13:167-173

Niklewski J, Fredriksson M, Isaksson T (2016) Moisture content prediction of rain-exposed wood: test and evaluation of a simple numerical model for durability applications. Build Environ 97:126-136

Norberg P (1999) Monitoring wood moisture content using the WETCORR method. Part 1: background and theoretical considerations. Holz Roh- Werkst 57:448-453

Otten KA, Brischke C, Meyer C (2017) Material moisture content of wood and cement mortars-electrical resistance-based measurements in the high ohmic range. Constr Build Mater 153:640-646

Saito H, Fukuda K, Sawachi T (2012) Integration of hygrothermal analysis with decay process for durability assessment of building envelopes. Build Simul 5:315-324

Skaar C (1988) Wood-water relations. Springer, Berlin

Stamm AJ (1929) The fiber-saturation point of wood as obtained from electrical conductivity measurements. Ind Eng Chem Anal Ed 1:94-97

Time B (1998) Hygroscopic moisture transport in wood. Dissertation. Norwegian University of Science and Technology

Viitanen H, Toratti T, Makkonen L, Peuhkuri R, Ojanen T, Ruokolainen L, Räisänen J (2010) Towards modelling of decay risk of wooden materials. Eur J Wood Prod 68:303-313

Wadsö L (1993) Surface mass transfer coefficients for wood. Dry Technol 11(6):1227-1249

Wang SY, Lin SJ (1991) The effect of outdoor environmental exposure on the main components of wood. Mokuzai Gakkaishi 37(10):954-963

Welzbacher C, Rapp AO (2004) Determination of water sorption properties and preliminary results from field tests above ground of thermally modified material from industrial scale processes. IRG/WP 04-40279

Yamamoto H, Sakagami H, Kijidani Y, Matsumura J (2013) Dependence of microcrack behavior in wood on moisture content during drying. Adv Mater Sci Eng. https://doi.org/10.1155/2013/802639

Zelinka SL, Wiedenhoeft AC, Glass SV, Ruffinatto F (2015) Anatomically informed mesoscale electrical impedance spectroscopy in southern pine and the electric field distribution for pin-type electric moisture metres. Wood Mater Sci Eng 10(2):189-196

Žlahtič M, Humar M (2016) Influence of artificial and natural weathering on the moisture dynamics of wood. BioResources 12:117-142

Publisher's Note Springer Nature remains neutral with regard to jurisdictional claims in published maps and institutional affiliations. 


\section{Affiliations}

\section{J. Niklewski ${ }^{1}\left[\right.$ - C. Brischke ${ }^{2}$. E. Frühwald Hansson ${ }^{1}$ - L. Meyer-Veltrup ${ }^{3}$}

C. Brischke

christian.brischke@uni-goettingen.de

E. Frühwald Hansson

eva.fruhwald_hansson@kstr.lth.se

L. Meyer-Veltrup

meyer@hpi-hannover.de

1 Division of Structural Engineering, Lund University, John Ericssons Väg 1, PO-Box 118, 22363 Lund, Sweden

2 Department Wood Biology and Wood Products, University of Goettingen, Buesgenweg 4, 37077 Göttingen, Germany

3 Heinz-Piest-Institute for Skilled Crafts, Wilhelm-Busch-Straße 18, 30167 Hannover, Germany 